\title{
Treatment of Osteoporosis with Parathyroid Hormone and Teriparatide
}

\author{
Johannes Pleiner-Duxneuner · Elisabeth Zwettler • \\ Eleftherios Paschalis · Paul Roschger · \\ Valerie Nell-Duxneuner · Klaus Klaushofer
}

Published online: 11 September 2009

(C) Springer Science+Business Media, LLC 2009

\section{Erratum to: Calcif Tissue Int \\ DOI 10.1007/s00223-009-9218-x}

After publication of the above-mentioned article, we detected an important mistake in the "Tolerability and Adverse Events" section of the manuscript. Due to a spellchecking software the term "hypocalcemia" was used instead of "hypercalcemia" several times in this section, especially in the paragraph about Teriparatide. The correct text for the section should be as follows:

\section{Tolerability and Adverse Events}

Overall, treatment with PTH or Teriparatide is well tolerated. Often adverse events derive from the role of PTH in calcium metabolism. Hypercalcemia and hypercalciurea could occur during PTH treatment and might require a dose reduction or discontinuation of treatment. However, unspecific adverse events like nausea and headache were also reported. ...

The online version of the original article can be found under doi:10.1007/s00223-009-9218-x.

J. Pleiner-Duxneuner · E. Zwettler · E. Paschalis ·

P. Roschger · V. Nell-Duxneuner - K. Klaushofer

4th Medicine Department, Hanusch Hospital,

Ludwig Boltzmann Institute of Osteology at the Hanusch

Hospital of WGKK and AUVA Trauma Centre Meidling,

1140 Vienna, Austria

J. Pleiner-Duxneuner $(\bowtie)$

Department of Clinical Pharmacology,

Medical University Vienna, Vienna, Austria

e-mail: johannes.pleiner@meduniwien.ac.at

\section{Teriparatide}

At the approved dose of $20 \mu \mathrm{g}$ per day, mild hypercalcemia $(\geq 2.6 \mathrm{mmol} / \mathrm{L})$ was reported to occur in $11 \%$ of women receiving Teriparatide, compared to $2 \%$ of women in the placebo group [27]. Higher doses of Teriparatide seem to be associated with a higher frequency of hypercalcemia. Twenty-eight percent of women receiving $40 \mu \mathrm{g}$ of Teriparatide in the study by Neer et al. were reported to have hypercalcemia. However, of the high serum calcium values, $95 \%$ were $<2.8 \mathrm{mmol} / \mathrm{L}$ in the $20-\mu \mathrm{g}$ group, and $95 \%$ were $<2.95 \mathrm{mmol} / \mathrm{L}$ in the $40 \mu \mathrm{g}$ group. In only about one-third of the women with high serum calcium concentrations were the values high upon retesting, and women who did not have hypercalcemia during the first 6 months of treatment seldom had it later. Therefore, treatment had to be withdrawn because of repeatedly elevated serum calcium concentrations in only one woman in the $20-\mu \mathrm{g}$ group and nine in the 40- $\mu$ g group [27]. ...

In contrast to Preotact, routine measurements of serum calcium are not recommended in the SPCs. After Teriparatide is discontinued, serum calcium levels usually return to normal in a few days. If oral calcium intake is reduced by $500 \mathrm{mg} /$ day, hypercalcemia usually does not recur after Teriparatide is restarted. The effect of treatment may be monitored by DXA scans after 18 months. The optimal follow-up program, however, remains to be determined. ... 